\title{
Study on the Girder-End Displacement of a Suspension Bridge Based on Field Measurements
}

\author{
Jinchao Zhang1, Xiaolong $\mathrm{Li}^{2}$, Chao Fang1, Xingquan $\mathrm{Mao}^{2}$, Wenyun $\mathrm{Li}^{2}$, Longyun $\mathrm{Li}^{2}$, $\mathrm{Yi} \mathrm{Zhou}^{3 *}$ \\ ${ }^{1}$ Qingyun Expressway Management Center of Guangdong Nanyue Transportation Investment and Construction Co., Ltd., \\ Guangzhou, China \\ ${ }^{2}$ CCCC Highway Consultants Co., Ltd., Beijing, China \\ ${ }^{3}$ Department of Civil Engineering, University of Science \& Technology Beijing, Beijing, China \\ Email: *lixiaolong@hpdi.com.cn, ${ }^{\star}$ zhouyi@ustb.edu.cn
}

How to cite this paper: Zhang, J.C., Li, X.L., Fang, C., Mao, X.Q., Li, W.Y., Li, L.Y. and Zhou, Y. (2021) Study on the Girder-End Displacement of a Suspension Bridge Based on Field Measurements. Open Journal of Civil Engineering, 11, 167-178. https://doi.org/10.4236/ojce.2021.112011

Received: March 9, 2021

Accepted: May 18, 2021

Published: May 21, 2021

Copyright () 2021 by author(s) and Scientific Research Publishing Inc. This work is licensed under the Creative Commons Attribution International License (CC BY 4.0).

http://creativecommons.org/licenses/by/4.0/

\begin{abstract}
The load-response correlation is a great concern for the management and maintenance agency of bridges. Based on both the load test data and the longterm structural health monitoring data, this study aims to characterize the variation in the girder-end longitudinal displacement of a long-span suspension bridge, i.e., the Zhaoyun Bridge in Guangdong Province of China. The load test provides a valuable chance to investigate the structural deformation in high loading levels, while the structural health monitoring system records the real-time, in-site, and long-term measurements in the normal operational stage of bridges. During the load test, the movement direction of the main girder is found to depend on the relative position of the center of gravity of the girder and the loading vehicles. However, over the period of normal operation, the quasi-static displacement at the ends of the main girder along the bridge axis is dominated by the temperature variations, rather than the traffic loading. The temperature-induced deformation is considerable so it should be filtered out from the structural total responses to highlight the live load effects or the anomalies of the bridge. As a case study, the temperature-displacement baseline model of the Zhaoyun Bridge is established and then utilized to identify the erroneous measurements in the structural health monitoring system. This paper serves as a reference for the structural behavior interpretation and performance evaluation of similar bridges.
\end{abstract}

\section{Keywords}

Suspension Bridge, Girder-End Displacement, Traffic Loading, Temperature Action, Load Test, Structural Health Monitoring 


\section{Introduction}

Suspension bridges are a type of bridge having the largest spanning ability but the least global stiffness [1] [2]. The structural deformation of such bridges under a wide variety of loads and actions has always been a hot research topic across both academia and industry [3] [4] [5]. In addition to theoretical analysis, scaled model testing, and numerical simulation, the field measurement research has made great progress in recent 20 years along with the development of structural health monitoring technology [6] [7]. Many suspension bridges have installed automatic data acquisition systems, which provide opportunities for recognizing the behavior of actual bridges under real load actions [8] [9].

The previous field measurements have shown that the ambient temperature variation generally dominates the operational deformation of long-span suspension bridges, such as the Tsing Ma [10], Jiangyin [11], Tamar [12], Runyang [13] suspension bridges. This is because the traffic level in every-day operation is usually much lower than the extreme conditions considered in the bridge design phase, and thus the live load effects tend to be masked by the temperature induced deformation. In terms of field measurements, the existing literatures mainly focus on the normal operation stage; however, there are relatively insufficient studies on the traffic-related quasi-static deformation as the extreme loading case is rare itself. In fact, the relative contribution of temperature and traffic actions to the structural deformation may vary significantly under different combinations of these two actions [14].

This paper analyzes the structural health monitoring data during both the load test and long-term operation of the Zhaoyun Bridge (also known as the Xijiang Bridge) to characterize the behavior pattern of the main girder displacement of suspension bridges. The load test provides valuable datasets for the study on structural deformation under high-level loading conditions, while the measurements in the routine operation period help to predict the structural performance evolution over a long period of time. The comparison between the above two cases expands the understanding of load-response correlation in a suspension bridge.

\section{The Zhaoyun Bridge}

The Zhaoyun Bridge is a $738 \mathrm{~m}$-main-span ground-anchored suspension bridge (Figure 1). It forms a key part of the Qingyuan-to-Yunfu section of the Shantou-to-Zhanjiang Expressway, which has been officially opened to traffic on Jan. $1^{\text {st }}, 2020$. The steel box girder has a span layout of $202+738 \mathrm{~m}$ with the width and depth being $34 \mathrm{~m}$ and $3 \mathrm{~m}$, respectively. The two main cables are of prefabricated parallel steel wire (PPSW) type and have the center-to-center spacing of $31.2 \mathrm{~m}$ in the transverse direction. The span arrangement of the main cable is $300+738+204 \mathrm{~m}$ and the sag-to-span ratio is 1:9 for the central span. Both towers adopt concrete portal frame structure with a total height of $160.229 \mathrm{~m}$. The standard spacing of the suspenders is $15 \mathrm{~m}$ along the bridge axis direction. 

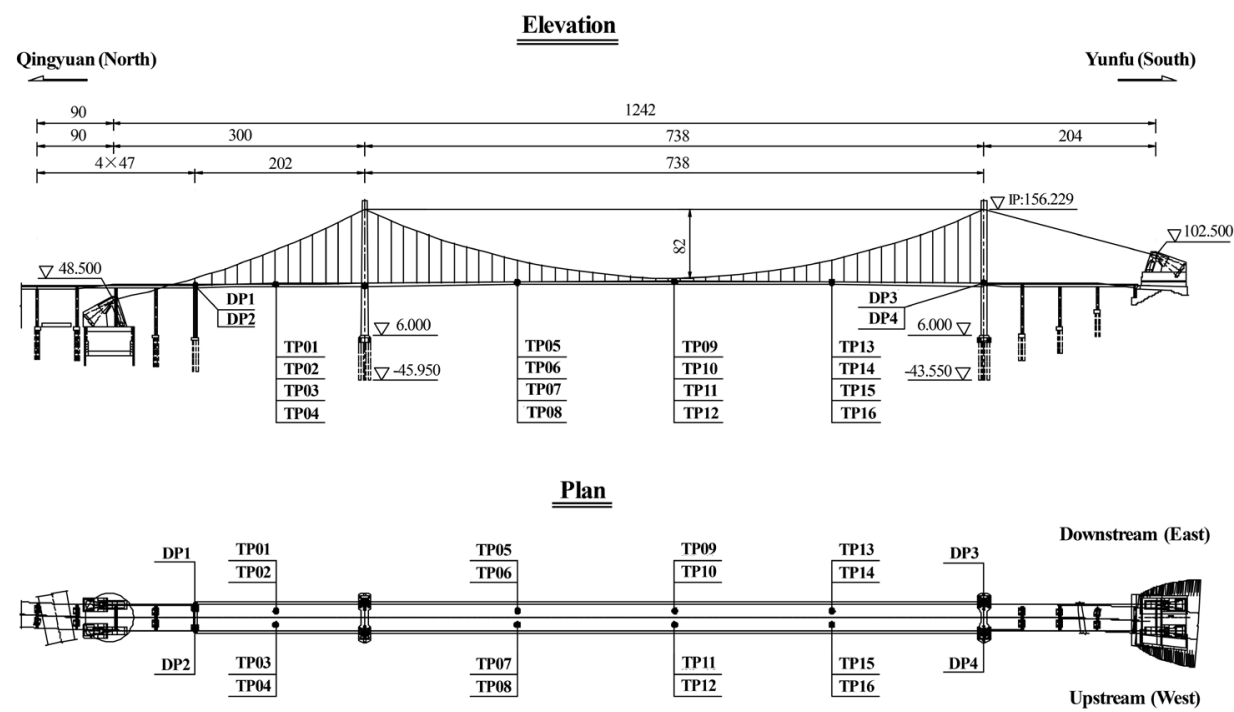

Figure 1. The Zhaoyun Bridge and the relevant sensor layout (unit: m; DP\#: extensometer; TP\#: temperature sensor).

The gravity anchorages are used to firmly anchor the main cables, and the anchor block on the Yunfu side is located above the route elevation as a result of topographic constraints. The boundary conditions of the steel box girder are as follows: 1) The lateral movement of the girder is restrained by the wind resistant bearings at both tower-girder intersections and the girder north end corresponding to the north transition pier; 2) Both girder ends are vertically supported by tension-compression bearings; 3) The longitudinal dampers are mounted at both tower-girder intersections, which could prevent high-frequency movement along the bridge axis yet allow the quasi-static longitudinal displacement [15].

In order to efficiently manage the long-term operation of the bridge, the bridge owner installed a comprehensive structural health monitoring system on the Zhaoyun Bridge, which was integrated into the construction, management, and maintenance online platform via the Building Information Modelling (BIM) technology [15]. The monitoring items include the environmental and operational actions, structural static and dynamic responses, and dynamic properties of the bridge. As a preliminary study, we focus on the variation in the girder-end horizontal displacements. The relevant sensors are illustrated in Figure 1. The horizontal displacement at the girder ends is positive when the concerned section moves southward (toward the Yunfu side).

\section{Load Test}

Before its open to public, an in-situ load test was performed on the Zhaoyun Bridge for structural evaluation in November, 2019, which includes the alignment measurement, static and dynamic load tests [16]. This section delves into the girder-end horizontal displacement during the static load test only.

The static load test has four load cases. Each case involves loading the bridge by gradually applying a different number of trucks (each weighing $350 \mathrm{kN}$ ) at 
specified locations, as shown in Figure 2. The concerned girder-end displacements are measured manually by survey crew using steel rulers. As the data is not continuous time series, this study resorts to the structural health monitoring data to review the complete picture of the structural behavior.

Figure 3 shows the evolution of the girder-end horizontal displacement along the bridge axis over the time period of November $26^{\text {th }}$ to December $1^{\text {st }}, 2019$. The data corresponding to Load Case 2 (LC2) was not well recorded due to the malfunction of the structural health monitoring system. The upstream and downstream displacements at the same end of the girder have similar variation patterns, thus indicating that the torsional effects of the cross sections around the

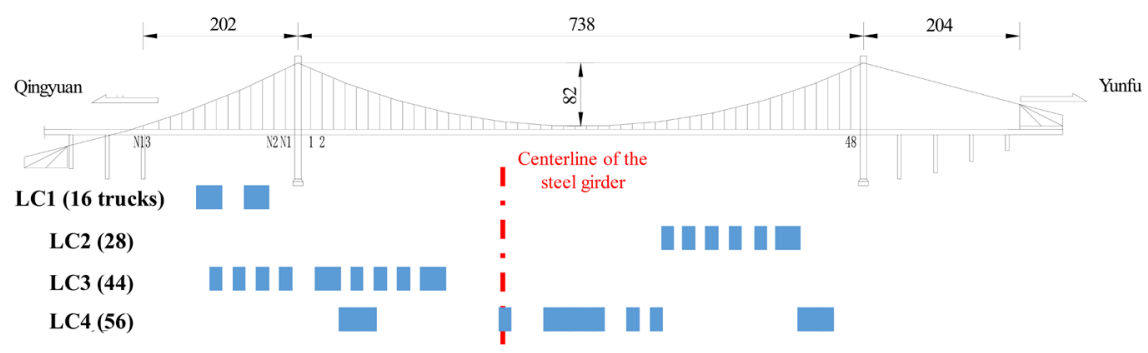

Figure 2. Longitudinal arrangement of trucks in four load cases (unit: m; : trucks).

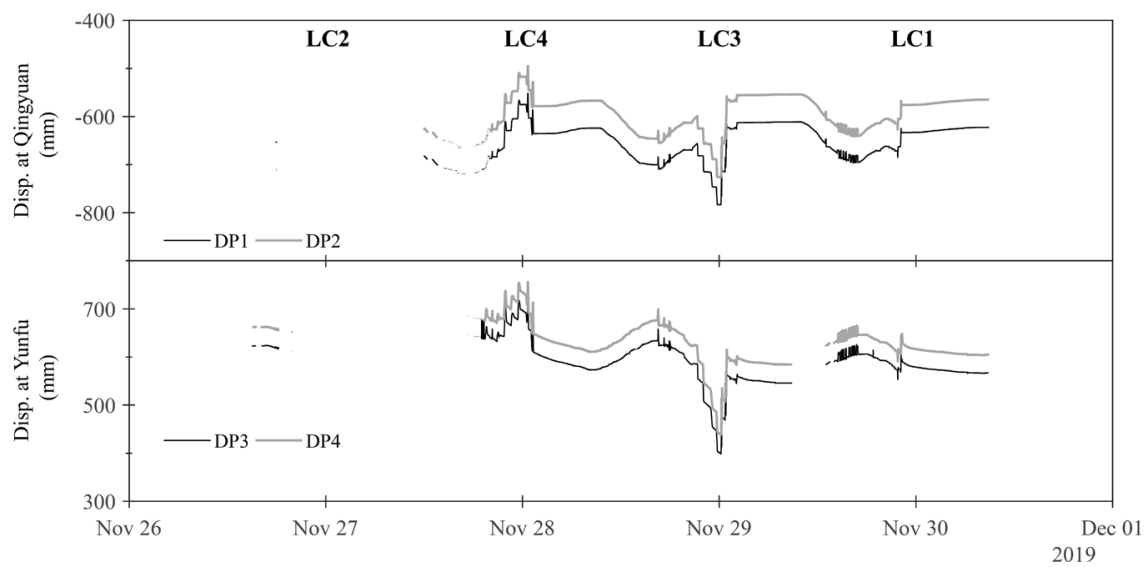

(a)

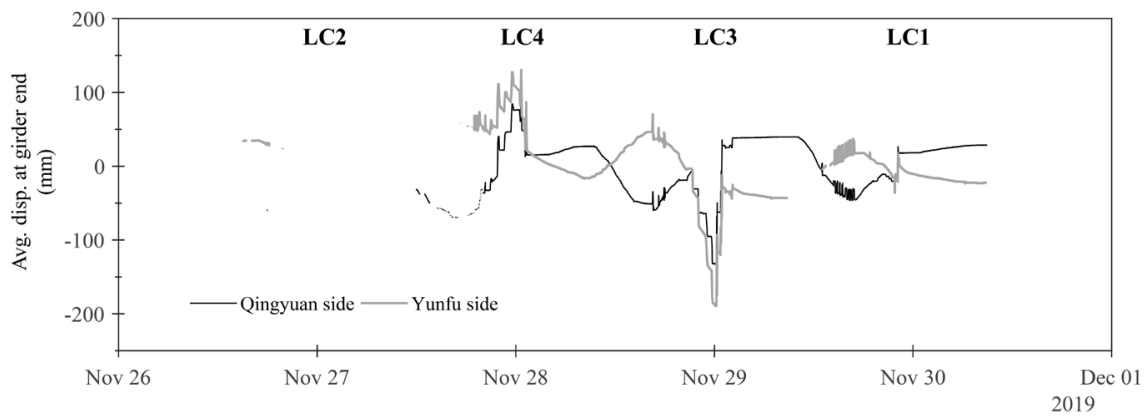

(b)

Figure 3. Time histories of the girder-end displacements with sampling frequency of 1 Hz. (a) Raw data; (b) Average of the upstream and downstream measurement (baseline adjusted to 0 ). 
vertical axis is negligible. The expansion and contraction of the girder can be represented by the averages of the measurements on the upstream and downstream sides (Figure 3(b)).

In Figure 3(b), the girder-end displacements at both ends exhibit a positive correlation (or in phase with each other) when the load is applied during midnight, while they show a negative correlation (or out of phase) during daytime when no trucks are on the bridge. As the loading position of trucks does not coincide with the center of gravity of the main girder, the girder would be driven by the trucks along the bridge axis. This subsequently results in identical movement direction of both ends of the girder during the load application. On the other hand, the temperature-induced girder expansion dominates in the daytime and therefore the girder-end horizontal displacements at Qingyuan and Yunfu sides have opposite variation trend.

If the truck and temperature-induced girder longitudinal displacements are respectively denoted as $y_{\mathrm{V}}$ and $y_{\mathrm{T}}$, then the Qingyuan-side displacement is $y_{\mathrm{qy}}=$ $y_{\mathrm{V}}-y_{\mathrm{T}}$ while the Yunfu-side is $y_{\mathrm{yf}}=y_{\mathrm{V}}+y_{\mathrm{T}}$. Consequently, we have $y_{V}=\left(y_{\mathrm{qy}}-\right.$ $y_{\mathrm{yf}} / / 2$ to estimate the truck-related girder longitudinal displacement.

Figure 4 shows the variation in $y_{V}$ for the load cases 1,3 , and 4 . Each load case divide the corresponding test load magnitude into 4 and 2 levels during the loading and unloading stages, respectively; and each load increment or reduction can be observed in the time histories of $y_{\mathrm{V}}$ except the Level 1 loading in LC1 (Figure 4(a)). This is because the total weight of loading trucks in LC1 is relatively small so that it cannot produce considerable longitudinal movement of the girder.

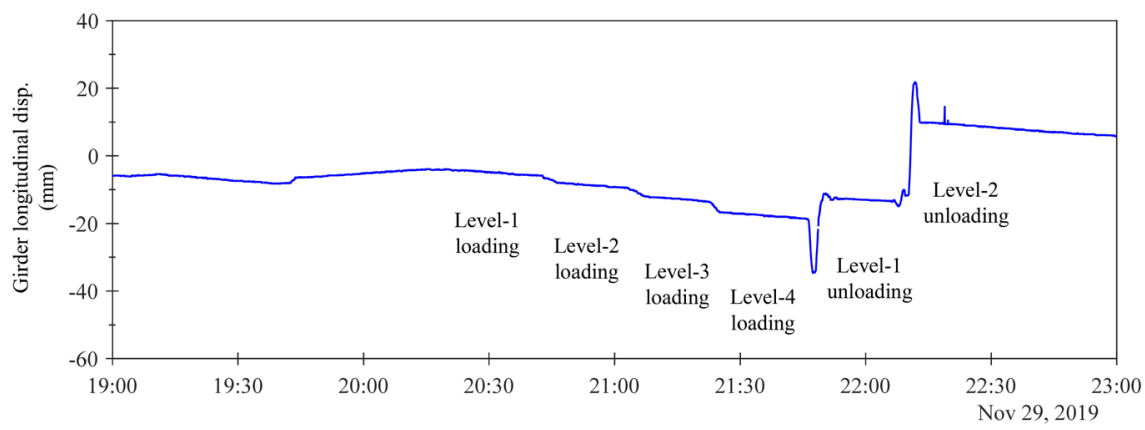

(a)

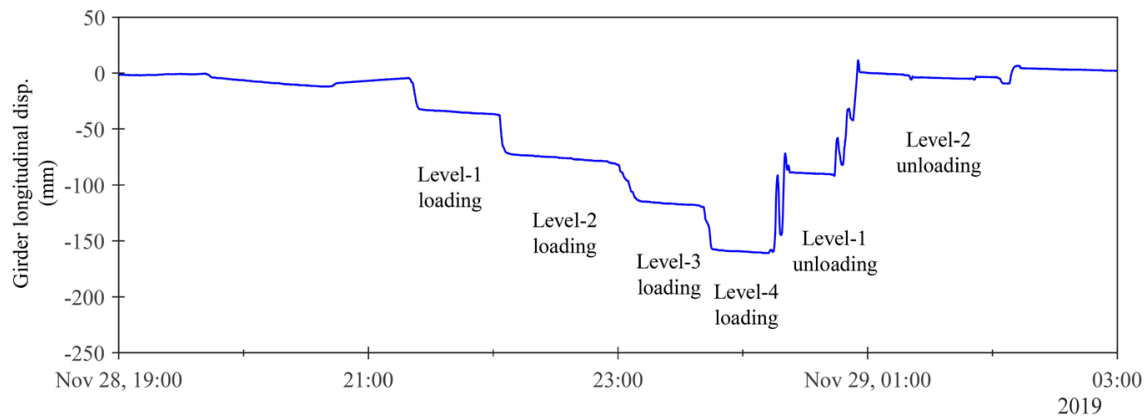

(b) 


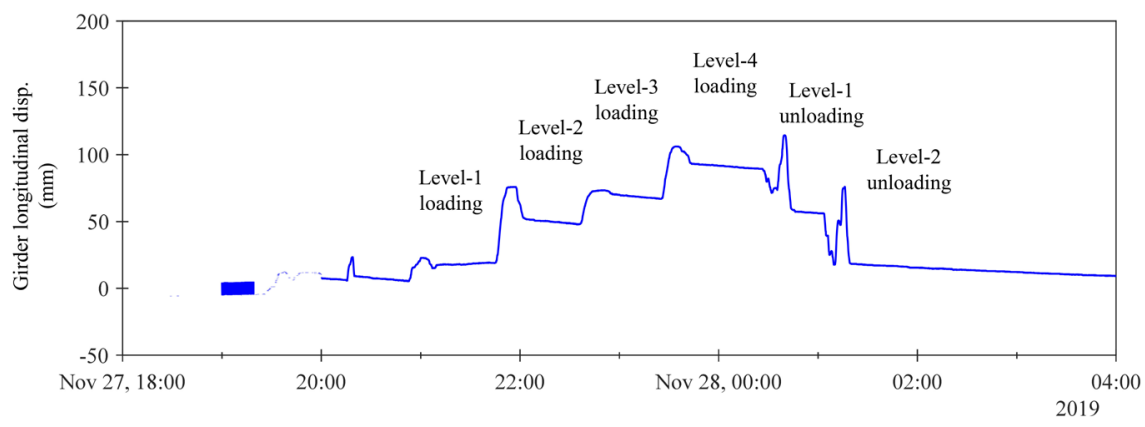

(c)

Figure 4. Truck-dependent longitudinal displacement at girder ends. (a) LC1; (b) LC3; (c) LC4.

Table 1 lists the girder-end horizontal displacements measured by the structural health monitoring system and by survey crew. The results of these two independent measuring systems are in good agreement, therefore validating the reliability of data. It can be seen that the main girder moves toward the Qingyuan side during LC1 and LC3, while toward the Yunfu side for LC4. The movement direction of the girder can be explained qualitatively by the relative position of the center of gravity (CG) of the loading vehicles with respect to that of the main girder. The dot dash line in Figure 2 indicates the CG of the steel girder, which is located to the south of the CG of the applied weights in LC1 and LC3. Due to the main cable's flexibility in suspension bridges, the main girder is driven by the loaded vehicles toward the south (to the Qingyuan side). On the contrary, the CG of the girder is to the north of vehicles in LC2 and LC4; therefore, the girder experiences a northward movement toward the Funyu side. Additionally, though the total vehicle weight of LC3 (having 44 trucks) is less than LC4 (56 trucks), the CG of trucks in LC3 is farther away from the CG of the main girder than LC4. As a result, LC3 causes a larger magnitude of the girder displacement than LC4 in the bridge axis direction.

\section{Normal Operation Period}

Since Jan. $1^{\text {st }}, 2020$, the Zhaoyun Bridge has been in normal operation. Figure 5 presents the time histories of the girder-end displacement at the Yunfu side from January to August, 2020. When we zoom in the period from Jan. $18^{\text {th }}$ to Feb. $10^{\text {th }}$, the diurnal variation of the displacement is very obvious, which is attributed to the daily temperature changes. In addition to the slowly-varying temperature effect, the girder displacement also has high frequency components caused by the traffics on the bridge. However, the traffic-induced displacement along the bridge axis is much smaller than the temperature influence. This is different from the situation in load test, where the truck-related effects dominate. Also, the period from Jan. $24^{\text {th }}$ to Feb. $1^{\text {st }}$ corresponds to the Spring Festival Holiday in China and the traffic volume across the Zhaoyun Bridge decreases considerably. As a result, the data curve over this period is much smoother than the other time duration, as shown in Figure 5(b). 
Table 1. Girder-end longitudinal displacement during the load test (Unit: mm).

\begin{tabular}{ccccccccc}
\hline \multirow{2}{*}{ Load cases } & \multicolumn{2}{c}{ LC1 } & \multicolumn{2}{c}{ LC2 } & \multicolumn{2}{c}{ LC3 } & \multicolumn{2}{c}{ LC4 } \\
\cline { 2 - 8 } & SHMS $^{\mathrm{a}}$ & Manually & SHMS $^{\mathrm{a}}$ & Manually & SHMS $^{\mathrm{a}}$ & Manually & SHMS $^{\mathrm{a}}$ & Manually \\
\hline Initial state & 0 & 0 & - & 0 & 0 & 0 & 0 & 0 \\
$\begin{array}{c}\text { Loading to } \\
\text { full test load }\end{array}$ & -13.3 & 8.3 & - & 243.5 & -152.8 & -147.8 & 84.1 & 78.8 \\
$\begin{array}{c}\text { Unloading to 0 } \\
14.1\end{array}$ & 14.8 & - & 17.8 & 6.3 & 10.5 & 9.9 & 9.3 \\
\hline
\end{tabular}

a. SHMS means the structural health monitoring system.

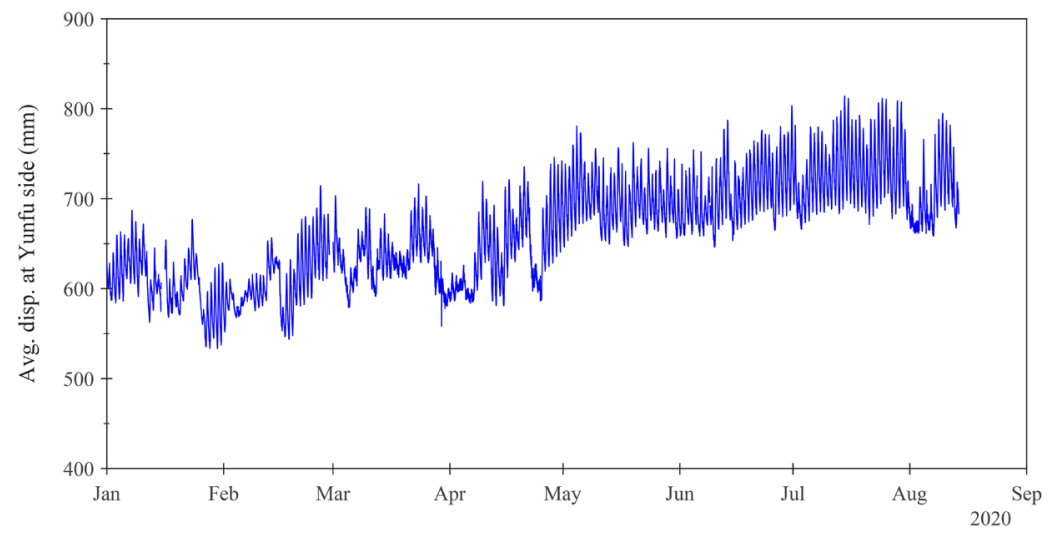

(a)

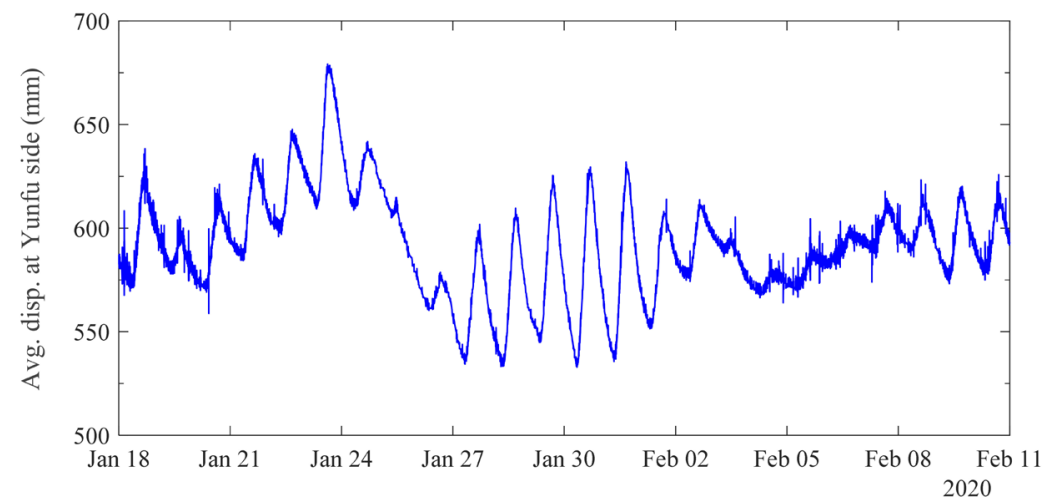

(b)

Figure 5. Girder-end longitudinal displacement at the Yunfu side in operational stage. (a) From January to August, 2020; (b) From Jan. 18th to Feb. 10th, 2020.

The above discussion implies that the temperature compensation is quite necessary in order to correctly interpret the measurement during the operational stage of bridges.

The temperature sensors are distributed at four cross sections along the bridge axis to measure the top plate temperature of the steel box girder (Figure 1). Figure 6 shows the temperature datasets with the sampling frequency being 10 $\mathrm{Hz}$. Compared with the displacement data; the temperature data has more anomalies such as outlier, drift, and missing data. The averaged girder temperature based on all temperature sensors is depicted in Figure 6(b), where the erroneous data is discarded. 


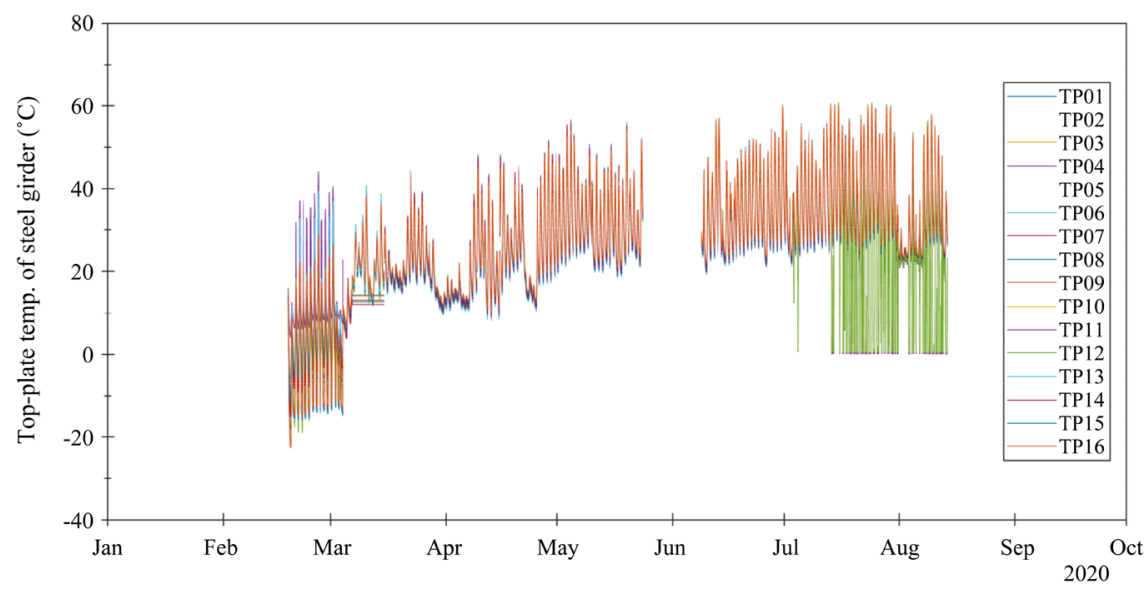

(a)

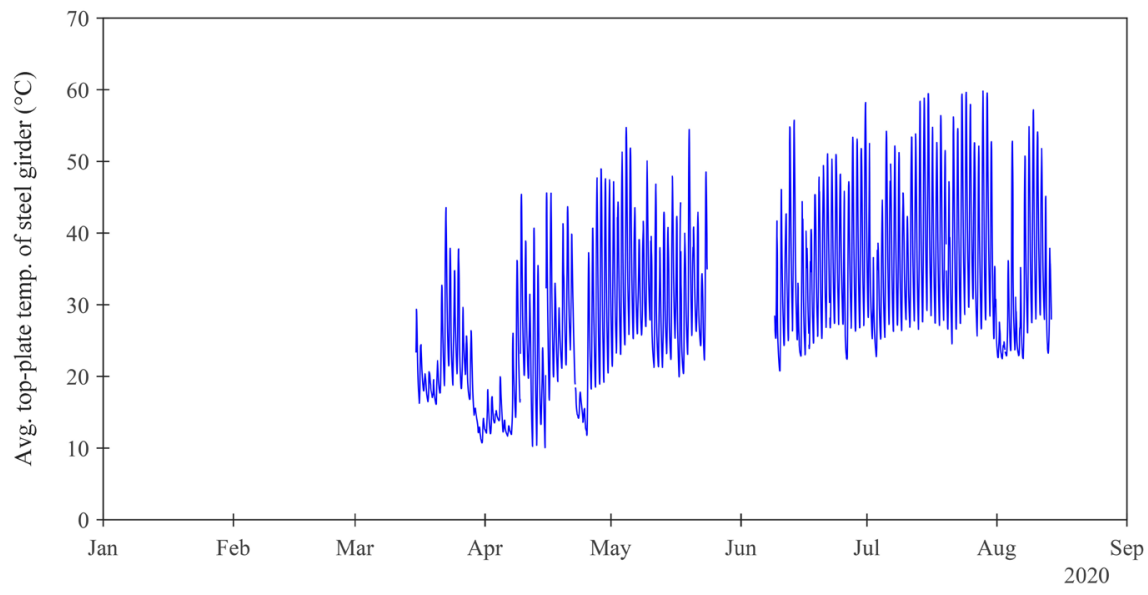

(b)

Figure 6. Top-plate temperature of the girder in operational stage. (a) Raw temperature dataset; (b) Average temperature across all sensors.

To evaluate the monitoring data quality in detail, the relationship between the temperature and girder-end displacement is investigated further in the next section.

\section{Data Anomaly Detection}

As shown in Figure 6(b), the time history of the girder temperature can be divided into two segments. The preliminary analysis indicates that the latter segment (from June to August) is more reliable, and is thus chosen to establish the baseline model of temperature-displacement relation.

Figure 7(a) is the scatter plot of the girder-end displacement at the Yunfu side with respect to the girder temperature, where the hourly averages of both temperature and displacement are used to filter out the traffic-related effects. As the distribution pattern of data points is primarily around an inclined line, a linear regression equation is fitted to describe the dependency of the girder-end displacement (denoted as $y$ ) on the top-plate temperature $(x)$ : 


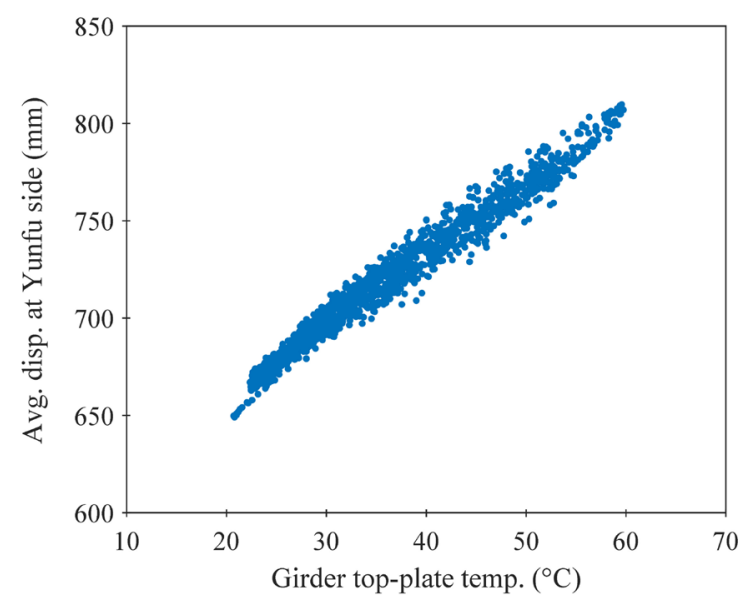

(a)

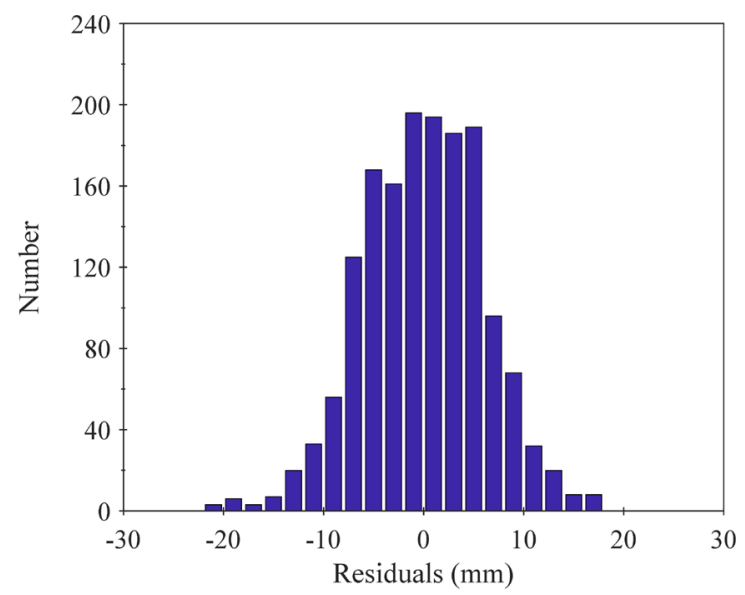

(b)

Figure 7. Regression modeling of the temperature vs. displacement based on data in Jun. - Aug., 2020. (a) Scatter plot of the temperature vs. displacement; (b) Histogram of the residual errors.

$$
y=3.60 x+589.10
$$

The fitted slope implies that the expansion of the girder on the Yunfu end is $3.6 \mathrm{~mm}$ when the top-plate temperature increases $1^{\circ} \mathrm{C}$. Theoretically, the temperature sensitivity of the girder-end displacement can be estimated by $\alpha \cdot L / 2$, where $\alpha$ and $L$ are respectively the linear expansion coefficient and the total length of the girder. As for the Zhaoyun Bridge, $\alpha=1.2 \times 10^{-5 \circ} \mathrm{C}^{-1}$ and $L=940$ $\mathrm{m}$, so the analytical sensitivity of the girder-end longitudinal displacement is $5.64 \mathrm{~mm} \cdot{ }^{\circ} \mathrm{C}^{-1}$, which is larger than the fitted slope $3.60 \mathrm{~mm} \cdot{ }^{\circ} \mathrm{C}^{-1}$. Note that the measured temperature is actually the top-plate temperature of the steel girder. It is severely affected by the direct sunlight during daytime and has a significantly higher variation range than the girder effective temperature. This is the reason why the fitted slope is less than the analytical sensitivity.

Figure $7(\mathrm{~b})$ is the histogram of the residual errors of Equation (1). The resi- 
duals mainly vary between $-20 \mathrm{~mm}$ and $20 \mathrm{~mm}$, and have a standard deviation of $\sigma=6.07 \mathrm{~mm}$, which will be used to determine the control limits in the following analysis.

By substituting the measured temperature into Equation (1), the calculated longitudinal displacement at the girder end can be obtained. It can be seen from Figure 8(a) that the calculated displacement deviates from the measured one prior to April 2020, and such a discrepancy becomes even more remarkable in Figure 8(b). The red dashed lines in Figure 8(b) represent the control limits corresponding to $\pm 3 \sigma$, which roots from the three-sigma rule of thumb in statistics. Around May $3^{\text {rd }}$, the difference between the calculated and measured values exceeds the range of $[-3 \sigma, 3 \sigma]$, thus indicating that the temperature-displacement relationship no longer satisfies Equation (1). The scatter plot in Figure 9 separates the dataset before May $3^{\text {rd }}$ from that after May $3^{\text {rd }}$, and validates the transition of the temperature-displacement patterns. The reasons behind the data anomaly will be further investigated in future.

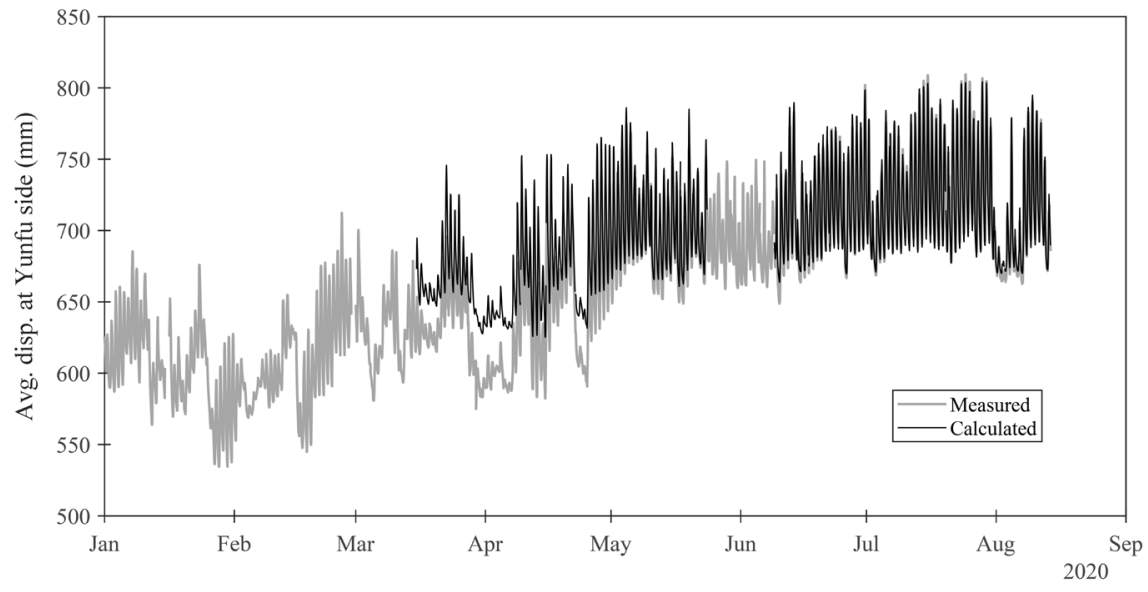

(a)

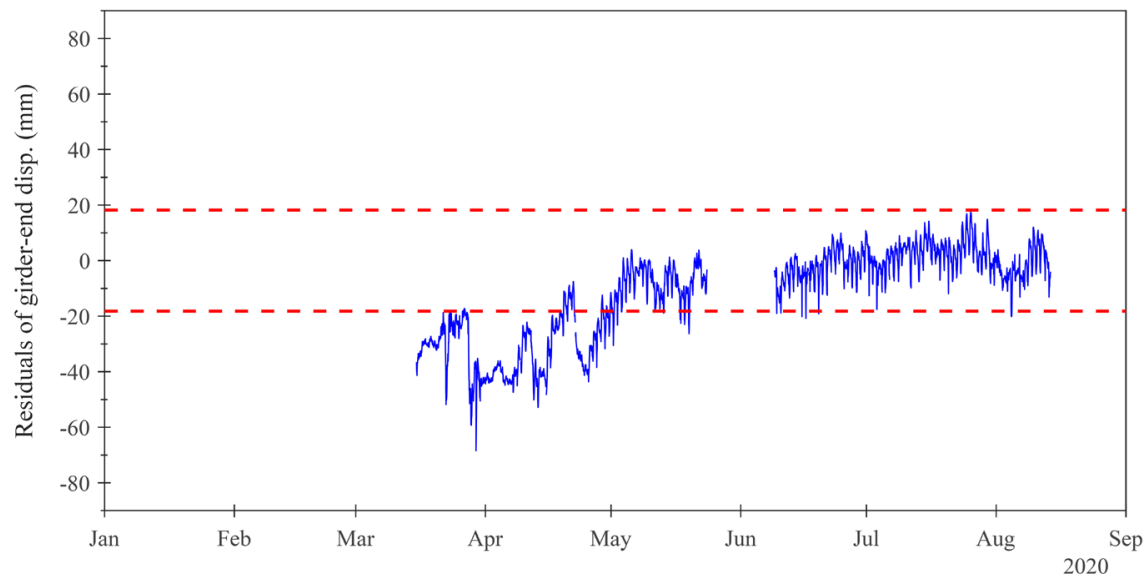

(b)

Figure 8. Comparison of the calculated and measured girder-end displacements. (a) Time history comparison; (b) The measured displacement minus calculated one. 


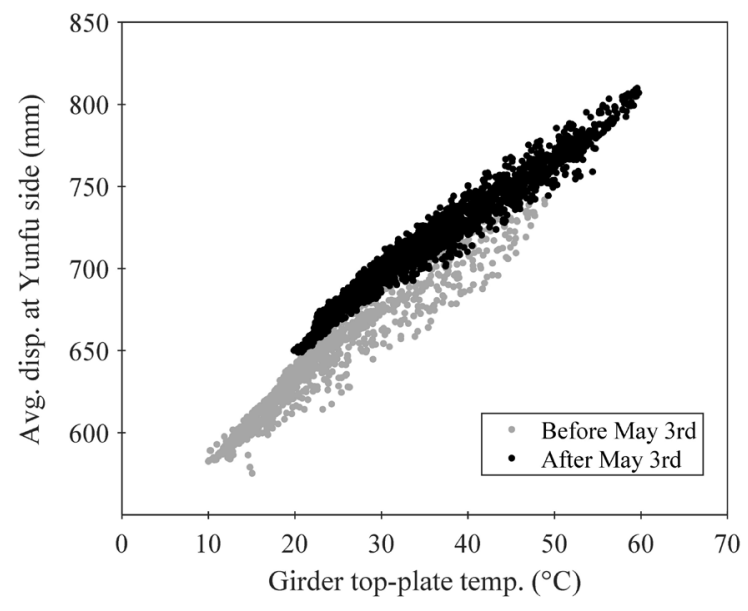

Figure 9. Scatter plot of the temperature vs. displacement during Jan.-Aug. 2020.

\section{Conclusions}

Based on the load testing and structural health monitoring data, this study investigates the quasi-static girder displacement of the Zhaoyun Bridge caused by loading vehicles and temperature changes. The main conclusions are as follows:

1) As a flexible structural system, the main girder of suspension bridges can be driven to move longitudinally by vehicles on it. The girder movement direction can be explained qualitatively by the relative position of the CGs of the girder and loading vehicles.

2) During the operational stage, the girder-end longitudinal displacement of the Zhaoyun Bridge is dominated by temperature variations, while the influence of normal traffics is insignificant. In order to estimate the live load effect correctly, the temperature-induced deformation should be eliminated from structural total responses.

3) Based on the mathematical models of both the thermal deformation and the corresponding residual errors, anomalies in the measurements can be identified so that the underlying causes can be further investigated. For the Zhaoyun Bridge, the bottom-plate temperature of the steel girder is suggested to be measured in the future, which helps to build a more accurate baseline model to quantify the thermal deformation.

\section{Conflicts of Interest}

The authors declare no conflicts of interest regarding the publication of this paper.

\section{References}

[1] Gimsing, N.J. and Georgakis, C.T. (2012) Cable Supported Bridges: Concept and Design. 3rd Edition, John Wiley \& Sons Ltd., Chichester, UK. https://doi.org/10.1002/9781119978237 
[2] Yanev, B. (2016) Suspension Bridges: An Overview. In: Alampalli, S. and Moreau, W.J., Eds., Inspection, Evaluation and Maintenance of Suspension Bridges, CRC Press, Florida, USA, 1-50.

[3] Ogihara, K. (2016) Design and Construction of Suspension Bridges. In: Alampalli, S. and Moreau, W.J., Eds., Inspection, Evaluation and Maintenance of Suspension Bridges, CRC Press, Boca Raton, Florida, USA, 51-68.

[4] Brownjohn, J.M.W., Koo, K., Scullion, A., et al. (2015) Operational Deformations in Long-Span Bridges. Structure and Infrastructure Engineering, 11, 556-574. https://doi.org/10.1080/15732479.2014.951857

[5] Rojas, E., Barr, P.J. and Halling, M.W. (2014) Bridge Response Due to Temperature Variations. Center for Advanced Infrastructure \& Transportation, Rutgers University, Logan.

[6] Fujino, Y., Siringoringo, D.M., Ikeda, Y., et al. (2019) Research and Implementations of Structural Monitoring for Bridges and Buildings in Japan. Engineering, 5, 1093-1119. https://doi.org/10.1016/j.eng.2019.09.006

[7] Bao, Y., Chen, Z., Wei, S., et al. (2019) The State of the Art of Data Science and Engineering in Structural Health Monitoring. Engineering, 5, 234-242.

https://doi.org/10.1016/j.eng.2018.11.027

[8] Xu, Y.L. and Xia, Y. (2011) Structural Health Monitoring of Long-Span Suspension Bridges. 1st Edition, Spon Press, Abingdon. https://doi.org/10.1201/b13182

[9] Zhou, Y., Xia, Y., Chen, B., et al. (2020) Analytical Solution to Temperature-Induced Deformation of Suspension Bridges. Mechanical Systems and Signal Processing, 139, Article ID: 106568. https://doi.org/10.1016/j.ymssp.2019.106568

[10] Xu, Y.L., Chen, B., Ng, C.L., et al. (2010) Monitoring Temperature Effect on a Long Suspension Bridge. Structural Control and Health Monitoring, 17, 632-653. https://doi.org/10.1002/stc.340

[11] Xia, Q., Zhang, J., Tian, Y., et al. (2017) Experimental Study of Thermal Effects on a Long-Span Suspension Bridge. Journal of Bridge Engineering, 22, Article ID: 4017034. https://doi.org/10.1061/(ASCE)BE.1943-5592.0001083

[12] Koo, K.Y., Brownjohn, J.M.W., List, D.I., et al. (2013) Structural Health Monitoring of the Tamar Suspension Bridge. Structural Control and Health Monitoring, 20, 609-625. https://doi.org/10.1002/stc.1481

[13] Deng, Y., Li, A.Q. and Ding, Y.L. (2009) Research and Application of Correlation between Beam End Displacement and Temperature of Long-span Suspension Bridge. Journal of Highway and Transportation Research and Development, 26, 54-58. (In Chinese)

[14] Westgate, R., Koo, K.Y., Brownjohn, J., et al. (2014) Suspension Bridge Response Due to Extreme Vehicle Loads. Structure and Infrastructure Engineering, 10, 821-833. https://doi.org/10.1080/15732479.2013.767844

[15] CCCC Highway Consultants Co., Ltd. (2019) Research on the Construction, Management, and Maintenance Integrated Platform Technology Based on BIM Technology for the Xijiang Bridge on the Qingyuan-to-Yunfu Section of the Shantou-to-Zhanjiang Expressway. (In Chinese)

[16] Testing Center of Guangdong Communications Group (2020) Load Test Report of the Main Bridge of the Xijiang Bridge on the Qingyuan-to-Yunfu Section of the Shantou-to-Zhanjiang Expressway. (In Chinese) 